\title{
Estudo das Manifestações Patológicas nas Passarelas da Região Metropolitana do Recife-PE
}

\author{
Study of Pathological Manifestations in the Catwalks of the Metropolitan Region of \\ Recife-PE
}

\section{José Edeilson da Silva França ${ }^{1}$ (i) orcid.org/0000-0003-1814-1592}

\section{Eliana Cristina Barreto Monteiro2,3 (id orcid.org/0000-0003-0842-779x}

\footnotetext{
${ }^{1}$ Escola Politécnica de Pernambuco, Universidade de Pernambuco, Recife, Brasil,

2 Departamento de Engenharia Civil, Universidade de Pernambuco, Recife, Brasil,

${ }^{3}$ Departamento de Engenharia Civil, Universidade Católica de Pernambuco, Recife, Brasil.

E-mail do autor principal: edeilson2006@hotmail.com
}

\section{RESUMO}

\begin{abstract}
A Região Metropolitana do Recife-PE está entre as capitais onde o transito é considerado um dos mais congestionados do país e algumas obras são extremamente importantes para que o engarrafamento não cresça. As passarelas, que são Obras de Artes Especiais, permitem essa fluidez, evitando as paradas ou interrupções para as travessias de pedestres, além de garantir a segurança destes. A falta de manutenção pode pôr em risco essa garantia, pois o que foi observado com este estudo é um estado de abandono dessas estruturas que são muito importantes. O objetivo do trabalho foi estudar as manifestações patológicas encontradas nas passarelas da Região Metropolitana do Recife. Observou-se que são várias manifestações, porém a corrosão de armadura é muito marcante principalmente na passarela do Engenho do Meio que apresenta, em alguns pilares, a armadura completamente exposta com perda de seção ou aço rompido. Em Paratibe as passarelas são do tipo estaiadas, uma verdadeira Obra de Arte, mas a falta de cuidado é tão evidente que um dos cabos de sustentação da estrutura já está rompido e os demais cabos apresentam um estado bem avançado de corrosão. Enfim, com o estudo realizado nessas estruturas percebe-se a importância de vistorias periódicas que podem ser uma das ferramentas para indicar os locais onde é necessário a intervenção imediata, evitando um custo elevado na manutenção com a interrupção do uso ou demolição dessas Obras de Artes Especiais.
\end{abstract}

PALAVRAS-CHAVE: Vistoria; Manifestação; Patológica; Corrosão; Passarelas.

\begin{abstract}
The Metropolitan Region of Recife-PE is among the capitals where transit is considered one of the most congested in the country and some works are extremely important so that bottling does not grow. The walkways, which are Works of Special Arts, allow this fluidity, avoiding stops or interruptions for pedestrian crossings, as well as ensuring their safety. The lack of maintenance can jeopardize this guarantee, because what was observed with this study is a state of abandonment of these structures that are very important. The objective of this study was to study the pathological manifestations found in the catwalks of the Metropolitan Region of Recife. It was observed that they are several manifestations, but the corrosion of armor is very striking mainly in the catwalk of the Engenho do Meio that presents, in some pillars, the armature completely exposed with loss of section or steel ruptured. In Paratibe the walkways are of the stationary type, a real work of art, but the lack of care is so evident that one of the support cables of the structure is already broken and the other cables present a well advanced state of corrosion. Finally, the study carried out in these structures shows the importance of periodic surveys that can be one of the tools to indicate the places where immediate intervention is necessary, avoiding a high maintenance cost with the interruption of the use or demolition of these Works of Arts Specials.
\end{abstract}




\section{KEY-WORDS: Survey; Manifestation; Pathological; Corrosion; Footbridges.}

\section{INTRODUÇÃO}

O termo patologia é oriundo da medicina que significa $o$ estudo das doenças e suas consequências no corpo humano, esse termo também é utilizado na construção civil de modo geral, como sendo o estudo das doenças e suas consequências no sistema ou subsistema [1].

Segundo Helene [2], "patologia é a parte da engenharia que estuda os sintomas, os mecanismos, as causas e as origens dos defeitos das construções civis, ou seja, é o estudo das partes que compõem o diagnóstico do problema".

Essas doenças nas estruturas de concreto armado podem aparecer de diversas formas é maneira que a estrutura encontrou de informar que necessita de reparos ou recuperação.

Conforme o Manual de Manutenção de Obras de Artes Especiais (OAEs) do DNIT (2016) [7] "as passarelas são destinadas, essencialmente, ao tráfego de pedestres e, eventualmente, ao de ciclistas. Sempre que crescer a importância de separar o tráfego de veículos do cruzamento de pedestres, aumentando a segurança dos pedestres e facilitando o fluxo de tráfego, faz-se necessária a construção de uma passarela. "

A Região metropolitana do Recife-PE é composta por várias passarelas, (OAEs), essas estruturas são fundamentais para as pessoas que precisam atravessar as avenidas ou BRs muito movimentadas, como também para o fluxo de veículos que não precisam parar em semáforos ou faixas de pedestres.

Em 2018, foi retirada, por não ter mais condições de uso e o custo com manutenção ou recuperação não ser viável, a passarela da BR 101 que ficava na frente do hospital das clinicas no bairro da Cidade Universitária. A remoção da $O A E$ causou grandes mudanças no local, pois foi substituída por uma faixa de pedestre e um semáforo. Esses equipamentos são bastantes eficientes, porém não em vias movimentadas como a BR 101, pois deixam os usuários mais exposto a possíveis acidentes, além de congestionar o trafego nesse local que já é muito intenso.

É importante lembrar que o Recife é uma das capitais com o maior transito do pais, a retirada ou falta de manutenção de equipamentos que auxiliam a transposição de grandes vias ou BRs nos colocam cada vez mais em uma posição acima no ranking e isso não é nada bom para o transporte nem para a qualidade de vida daqueles que usam as vias ou moram nas proximidades.

Segundo Vitório [12] " as vistorias das obras de Arte Especiais devem ser constituídas das seguintes etapas: Inspeção da obra, análise do projeto original (ou das modificações, se for o caso) e relatório final. "

Conforme o Manual de Manutenção de Obras de Artes Especiais (OAEs) do DNIT [7], as inspeções rotineiras podem identificar as manifestações patológicas ainda na fase inicial, sendo possível a correção ou manutenção sem comprometer a condição de serviço da estrutura, pois a falta desta inspeção pode incidir na lei dos custos, conhecida como lei de Sitter, que diz que os custos com correção crescem com uma progressão geométrica de razão 05 (cinco).

Diante do exposto essa pesquisa faz um estudo das principais manifestações patológicas em 05 (cinco) passarelas da BR 101, entre os trechos de Jaboatão dos Guararapes a Paulista, cidades que fazem parte da Região Metropolitana do Recife-PE, focando nos principais tipos de manifestações, danos e causas.

\section{ORIGEM DAS MANIFESTAÇÕES PATOLÓGICAS}

Segundo Souza e Ripper [3], "Quando o projeto de engenharia for mal detalhado, a construção for realizada com insuficientes planejamento e controle, os técnicos e operários não forem dotados da qualificação adequada e os prazos de execução forem excessivamente curtos, a estrutura de concreto resultante será quase certamente de má qualidade e irá se deteriorar de modo prematuro, absorvendo gastos de recuperação e de reforço exagerados para ser mantida em condições de uso".

Monteiro [11], define a origem das manifestações patologias conforme a quadro 1 .

Quadro1: Origem de Manifestação patológica. 


\begin{tabular}{|l|l|}
\hline Manifestação & \multicolumn{1}{|c|}{ Origem } \\
\hline Congênitas & Fase de projeto. \\
\hline Construtivas & Fase de execução. \\
\hline Adquirida & Agressividade do meio. \\
\hline Acidentais & $\begin{array}{l}\text { Fenômenos atípicos como Erosão, } \\
\text { inundações ou Cargas excessivas. }\end{array}$ \\
\hline
\end{tabular}

Fonte: adaptada [11].

\subsection{Tipos, causas e consequências das Manifestações patológicas}

A Figura 1 mostra os tipos de manifestações patológicas mais comum em estruturas, causas e consequências.

\begin{tabular}{|c|c|c|}
\hline PATOLOGIAS & CAUSAS & CONSEQUÊNCIAS \\
\hline CARBONATAÇÃO & POLUIÇÃ̄O $\left(\mathrm{CO}_{2}\right)$ & ACIDEZ NO CONCRETO \\
\hline CALCINAÇÃo & INCÊNDIO & REDUÇÃO DO $f_{d}$ \\
\hline $\begin{array}{l}\text { LLXIVIACCÃO E } \\
\text { FLORESCÊNCIA }\end{array}$ & $\begin{array}{l}\text { - INFILTRAÇ̄̃ES, POROSIDADE, } \\
\text { - TRINCAS, } \\
\text { - JUNTAS DE DILATAÇÃO } \\
\text { SEM ESTANQUEIDADE }\end{array}$ & $\begin{array}{l}\text { REDUCCÃO DO CALCÁREO } \\
\text { NO CONCRETO }\end{array}$ \\
\hline $\begin{array}{l}\text { NICHOS DE } \\
\text { CONCRETAGEM }\end{array}$ & VIBRAÇÃO INEFICAZ & $\begin{array}{l}\text { REDUÇÃO DA SEÇÃO } \\
\text { TRANSVERSAL DO CONCRETO }\end{array}$ \\
\hline \begin{tabular}{|l|} 
RUPTURA BRUSCA DO \\
CONCRETO COMPRIMIDO
\end{tabular} & $\begin{array}{l}\text { FALTA DE CONTROLE } \\
\text { ESTATISTICO DO CONCRETO }\end{array}$ & $\begin{array}{l}\text { COLAPSO PARCIAL } \\
\text { OU TOTAL }\end{array}$ \\
\hline $\begin{array}{l}\text { TRINCAS EM } \\
\text { ESTRUTURAS DE } \\
\text { COBERTURA }\end{array}$ & $\begin{array}{l}\text { - FALTA DE JUNTAS DE DILATAÇÃO, } \\
\text { - AUSÉNCIA DE TELHADO, } \\
\text { - NÃO CONSIDERACCÃO DOS } \\
\text { MOMENTOS VOLVENTES }\end{array}$ & $\begin{array}{l}\text { TRINCAS E CORROSÃO } \\
\text { DAARMADURA }\end{array}$ \\
\hline $\begin{array}{l}\text { CORROSÃO } \\
\text { DAARMADURA }\end{array}$ & 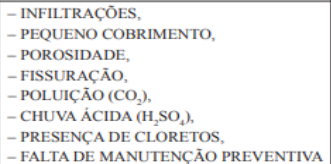 & $\begin{array}{l}\text { PERDA DE SEÇÃO } \\
\text { TRANSVERSAL DA } \\
\text { ARMADURA }\end{array}$ \\
\hline
\end{tabular}

Figura 1: Tipos de Manifestação patológica.

Fonte: [5].

* Corrosão da armadura

Para Monteiro [9], a" corrosão metálica em um meio aquoso é um fenômeno de caráter eletroquímico, isto é, supõe-se uma reação de oxidação e uma de redução a movimentação de elétrons através do metal, e a circulação de íons através do eletrólito, o que pressupõe a formação de um circuito fechado."

* Reação álcalis-agregado

Segundo Monteiro [10], as reações álcalis-agregado são reações químicas que ocorrem entre os íons alcalinos do Cimento Portland ou de outras fontes (álcalis), íons hidroxila e certos constituintes silicosos que podem estar presentes no agregado na presença de umidade.
* Carbonatação

A carbonatação é "a alteração dos compostos do cimento hidratado em carbonatos oriundo do ingresso de $\mathrm{CO} 2$ no concreto através da porosidade e fissuras no concreto " [6].

* Fissuras

Segundo Monteiro [8], os agentes agressivos usam as fissuras como portas abertas para o interior do concreto e através de alguns fatores como o microclima, se o concreto não tiver com um cobrimento suficiente para proteger a armadura o tempo de vida útil da estrutura pode ser reduzida significativamente.

* Vazios de concretagem

Ainda em Silva [6], o autor define como ninhos de concretagem (bicheiras), os espaços vazios causados por ausência ou excesso de vibração no concreto ainda no momento da execução.

* Eflorescências

Silva [6] é o processo que acontece quando a água infiltra pela estrutura dissolvendo os sais (Hidróxido de Cálcio) presentes no cimento e cal, após essa água evaporar, esses sais reagem com o dióxido de carbono no ar formando os depósitos.

* Bolor e vegetação

Para Shirakawa [13], "o termo bolor ou mofo são empregados para descrever a colonização por diversas grupos de fungos filamentosos sobre vários tipos de substratos, destacando-se, as argamassas inorgânicas. "

\subsection{Danos das Manifestações patológicas}

As manifestações patológicas podem causar desde um simples dano estético até um comprometimento estrutural inviabilizando o uso da estrutura. A Figura 2 classifica os tipos de danos causados pelas manifestações patológicas [11].

DOI: $10.25286 /$ repa.v5i3.1241 
Estudo das Manifestações Patológicas nas Passarelas da Região Metropolitana do Recife-PE

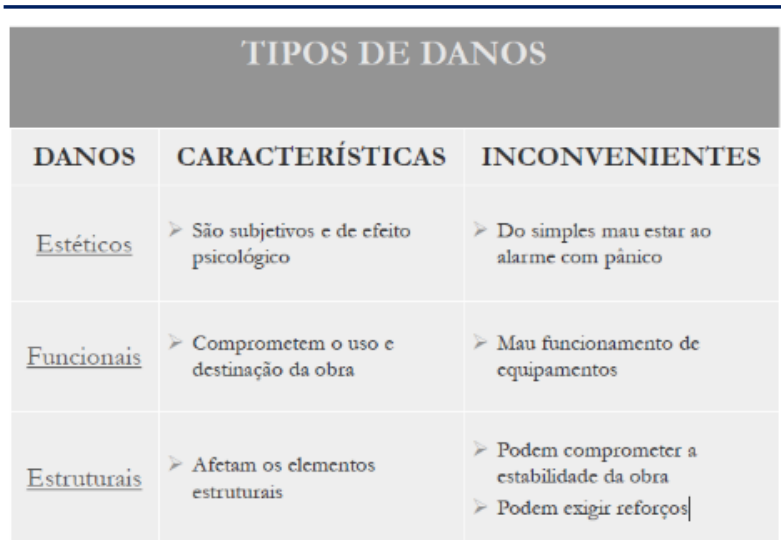

Figura 2: Tipos de Danos.

Fonte: [11].

\section{METOdOLOGIA}

Para a elaboração deste artigo foram realizadas inspeções visuais nas passarelas da Região Metropolitana do Recife-PE, trechos compreendidos entre o Ibura na cidade de Jaboatão dos Guararapes até Paratibe na cidade de Paulista.

Foram vistoriadas no total 05 (cinco) passarelas fazendo um levantamento das principais manifestações patológicas presentes na estrutura registrando por fotos essas manifestações.

\section{RESULTADOS}

As vistorias realizadas nas passarelas confirmam que a muito tempo essas estruturas não passam por manutenção, ou seja, o estado em que se encontram são de completo abandono, pois algumas não tem condições de serem usadas, seja pela falta de limpeza ou simplesmente elas não têm acesso.

A corrosão de armadura é vista em todas as OAEs vistoriadas. O quadro 2 mostra os tipos de manifestação mais encontrados nas OAEs. Todas as passarelas vistoriadas apresentaram patologias por falta de manutenção, sejam os tubos de drenos entupidos por lixo, folhas ou solo, falta de pintura de proteção ou revestimentos nos tabuleiros que não permita um acumulo de água reduzindo a infiltração.

\begin{tabular}{|c|c|c|c|c|c|}
\hline \multirow{2}{*}{ Tipo de Patologia } & \multicolumn{5}{|c|}{ Passarelas } \\
\cline { 2 - 6 } & Ibura & Ceasa & Engenho do Meio & Paratibe 1 & Paratibe 2 \\
\hline Corrosão de Armadura & $\mathrm{x}$ & $\mathrm{x}$ & $\mathrm{x}$ & $\mathrm{x}$ & $\mathrm{x}$ \\
\hline Eflorescência & $\mathrm{x}$ & $\mathrm{x}$ & $\mathrm{x}$ & $\mathrm{x}$ & $\mathrm{x}$ \\
\hline Lixiviação & $\mathrm{x}$ & $\mathrm{x}$ & $\mathrm{x}$ & $\mathrm{x}$ & $\mathrm{x}$ \\
\hline Fungos/Bolor/Vegetação & $\mathrm{x}$ & & & & \\
\hline Fissuras & $\mathrm{x}$ & $\mathrm{x}$ & $\mathrm{x}$ & $\mathrm{x}$ & $\mathrm{x}$ \\
\hline Nichos de concretagem (Vazios) & & & & & $\mathrm{x}$ \\
\hline Carbonatação & $\mathrm{x}$ & $\mathrm{x}$ & $\mathrm{x}$ & $\mathrm{x}$ & $\mathrm{x}$ \\
\hline
\end{tabular}

Quadro 2: Passarelas e Manifestação patológica. Fonte: Próprio Autor (2019)

A Figura 3 mostra que das 05 estruturas analisadas todas apresentam corrosão de armadura, lixiviação, eflorescência, fissuras e carbonatação. Em apenas duas OAEs foram observados fungos, vegetação e nichos de concretagem.

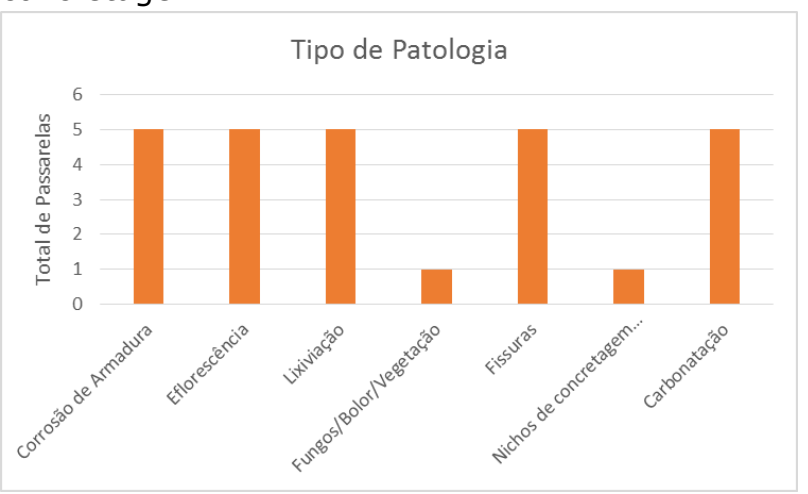

Figura 3: Tipos de patologias nas passarelas. Fonte: Próprio Autor (2019).

\subsection{Passarela da BR 101 no Ibura}

A passarela do Ibura é uma OAE pré-fabricada com três tabuleiros apoiados por vigas Gerber em dois pilares centrais. Nessa passarela a presença de corrosão de armadura, fungos e lixiviação é bem marcante. Também foram observados a falta de manutenção ou trocas das juntas metálicas com perdas de seção devido a corrosão.

Não foi feito nenhum ensaio para comprovar a carbonatação, porém a forma de desplacamento, a porosidade do concreto e o ambiente onde a estrutura se encontra não deixa dúvidas que esteja completamente carbonatada.

A falta de manutenção nas pingadeiras (tubos de dreno) é muito prejudicial para estrutura, pois a estrutura sendo lavada e os componentes do concreto sendo carreados. Os pilares apresentam fissuras e corrosão de armadura já com perda de seção de aço, conforme as Figuras 4 e 5 . A presença de fungos e pequenas vegetações na 
parte do tabuleiro desta estrutura podem ser observadas na Figura 6.

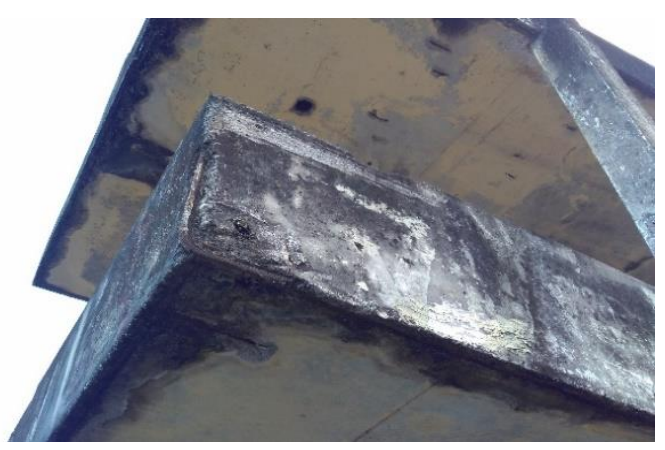

Figura 4: Lixiviação, tubo de dreno entupido. Fonte: Próprio Autor (2019).

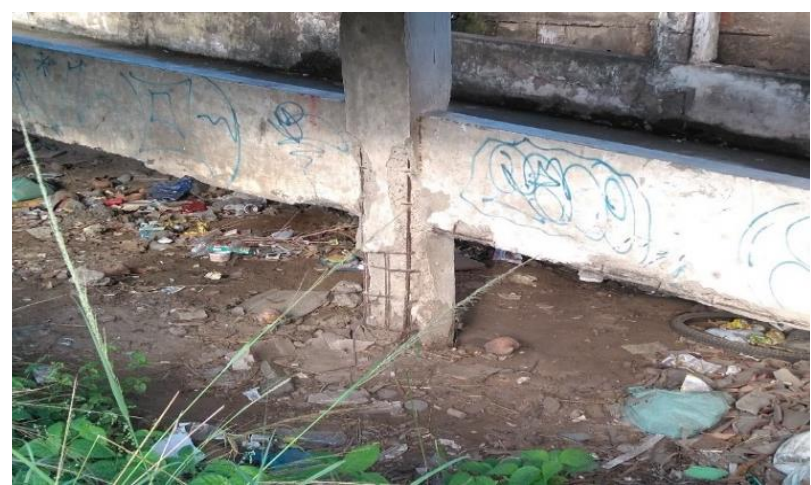

Figura 5: Corrosão de Armadura em pilar.

Fonte: Próprio Autor (2019).

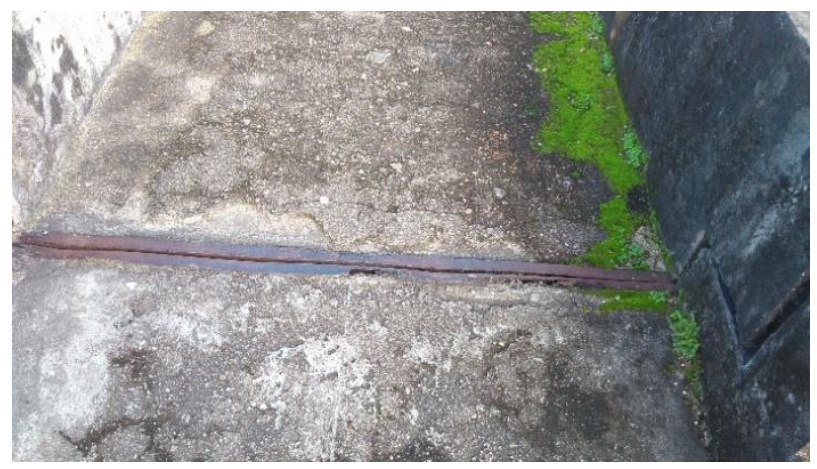

Figura 6: Fungos, vegetação junta deteriorada. Fonte: Próprio Autor (2019).

\subsection{Passarela da BR 101 em Paratibe}

Em Paratibe existem duas passarelas construídas de forma bem semelhantes. São estruturas estaiadas nas quais os cabos de aço suportam os esforços dos tabuleiros. As duas passarelas dão sinais de abandono, pois além da vegetação muito alta as rampas de acesso praticamente não existem. A passarela que fica no trecho mais ao sul, chamada nesse trabalho de Paratibe 1, apresenta um dos cabos de aço rompido e os demais cabos tendendo a romper como mostram as Figuras 7 e 8. Já as Figuras 9 e 10 mostram a dificuldade de acesso na Paratibe 2, além de vegetação e corrosão de armadura nos pilares laterais.

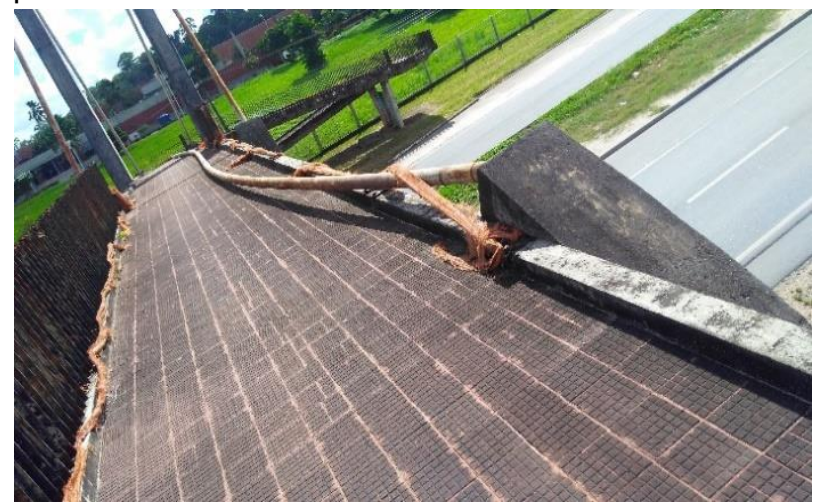

Figura 7: Cabo de aço rompido.

Fonte: Próprio Autor (2019).

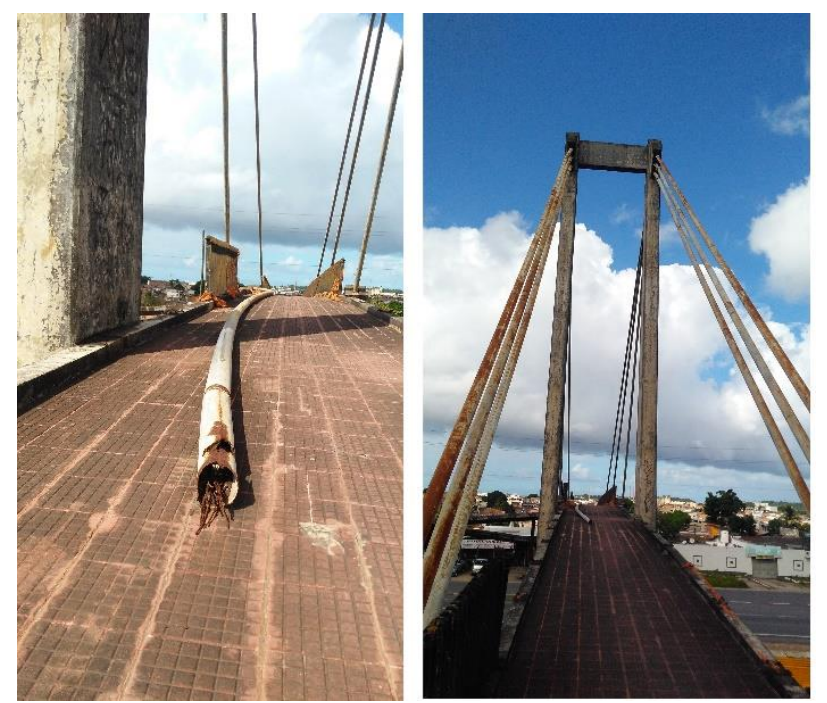

Figura 8: Corrosão de cabos de aço.

Fonte: Próprio Autor (2019). 


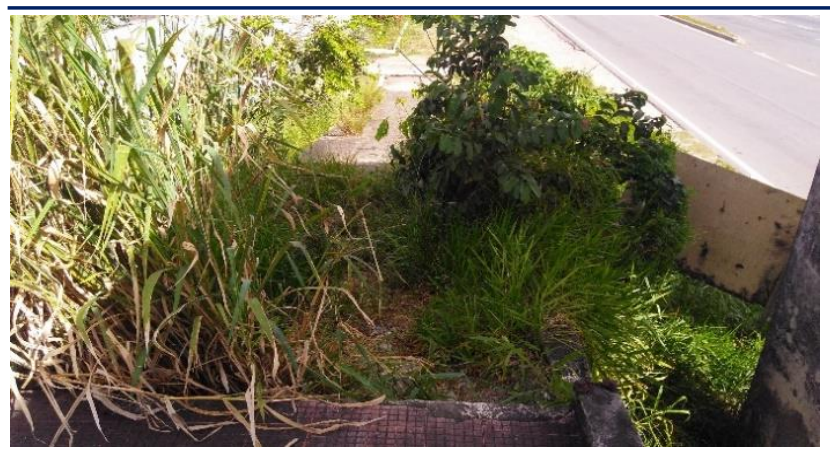

Figura 9: Vegetação na rampa de acesso.

Fonte: Próprio Autor (2019).

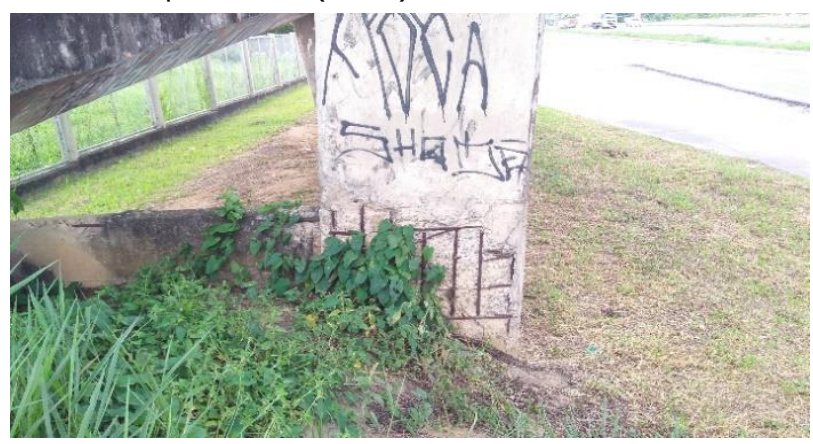

Figura 10: Corrosão de Armadura em pilar.

Fonte: Próprio Autor (2019).

O simples fato do tabuleiro ter revestimento cerâmico foi suficiente para protegê-lo contra infiltrações que ocorrem de forma pontual, reduzindo a lixiviação e eflorescência na parte inferior pode ser observada na Figura 11.

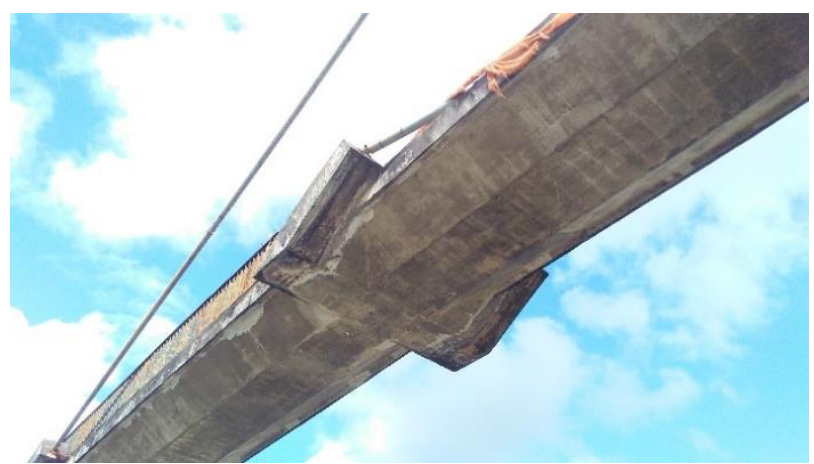

Figura 11: Parte inferior do tabuleiro da passarela. Fonte: Próprio Autor (2019).

As Figuras 12 e 13 mostram que nessa passarela o acesso é muito difícil o que comprova a falta de acessibilidade e manutenção destas OAEs, uma prova que as normas não estão sendo cumpridas nessas estruturas.

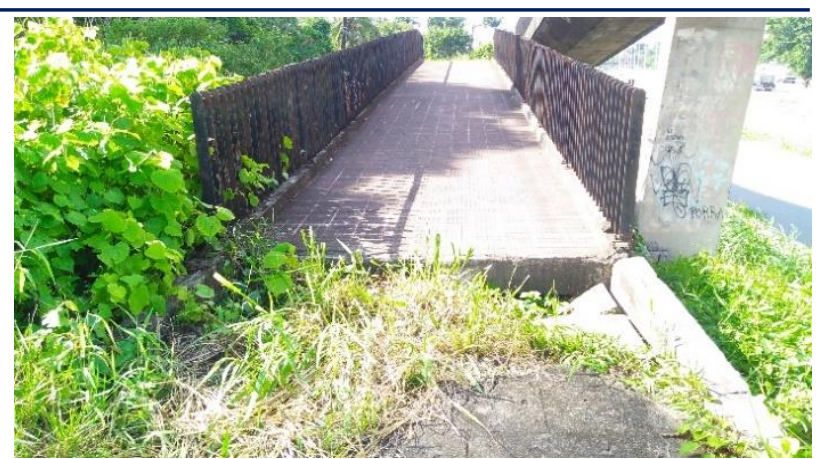

Figura 12: Rampa de acesso da passarela.

Fonte: Próprio Autor (2019).

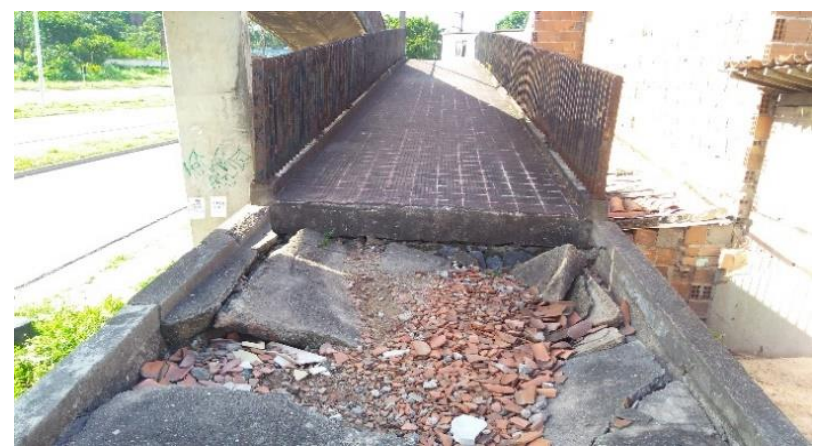

Figura 13: Rampa de acesso da passarela.

Fonte: Próprio Autor (2019).

\subsection{Passarela da BR 101 no Ceasa}

A passarela do Ceasa é uma das mais movimentada, ou seja, das mais usadas entre as OAEs vistoriadas. Essa estrutura apresenta boas condições de uso, apesar de algumas manifestações presentes a sua função não está comprometida. Essa passarela é a única que ainda apresenta sinais de pintura, porém não escondem as manifestações, mesmo com evidências de possíveis reparos em parte desta estrutura. A eflorescência, Lixiviação e Corrosão de Armadura podem ser vistos apenas na Figura 14.

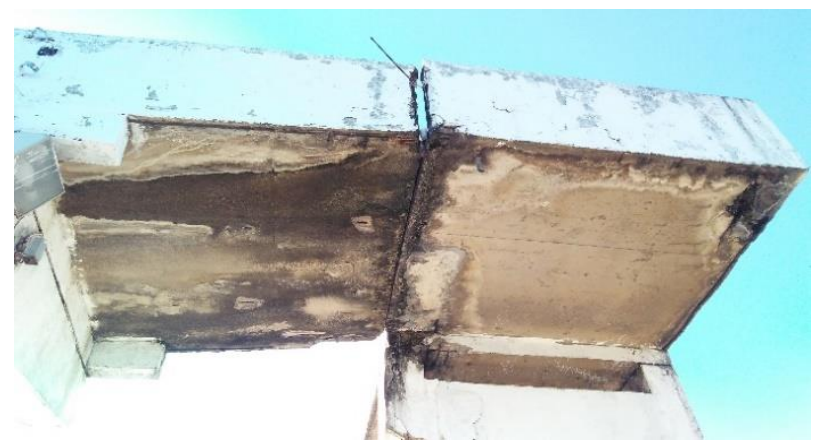

Figura 14: Lixiviação, corrosão e eflorescência. Fonte: Próprio Autor (2019). 
As juntas já não existem mais e a falta dessas faz com que a estrutura seja lavada sempre que chove. Essa água acaba carreando componentes do concreto causando grandes estragos, conforme a Figura 15, além de causar danos comprometedores na $\mathrm{OAE}$, tornando o ambiente propício a corrosão e exposição de armadura o que pode ser observado na Figura 16.

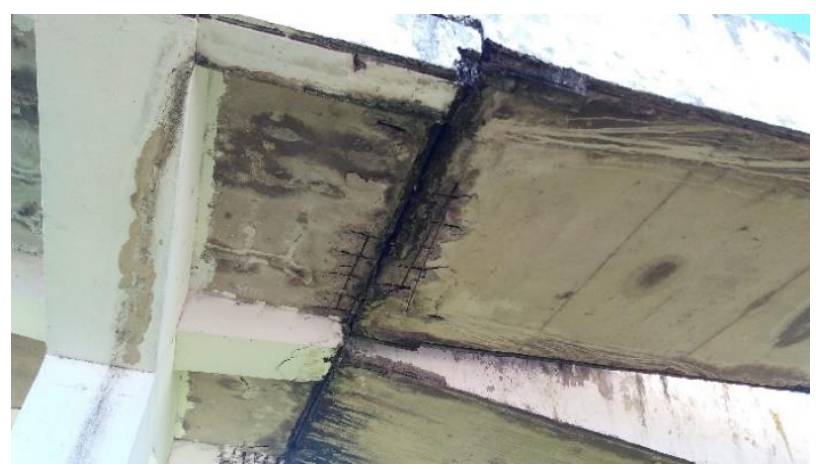

Figura 15: Falta de juntas e impermeabilização.

Fonte: Próprio Autor (2019).

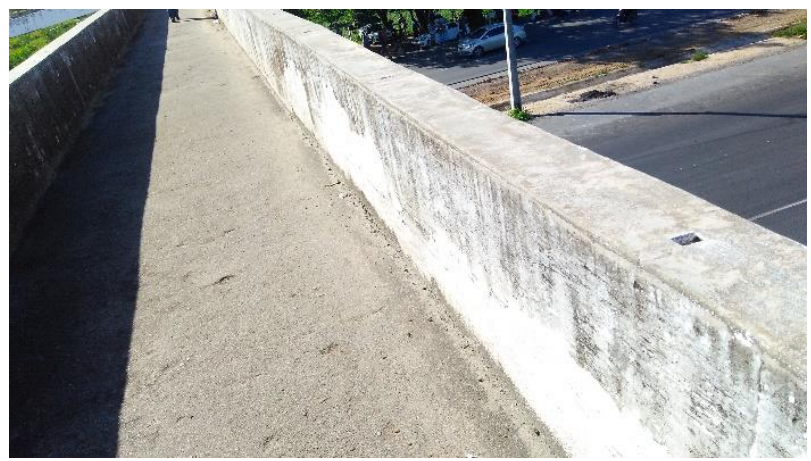

Figura 16: Trechos de possíveis recuperações.

Fonte: Próprio Autor (2019).

\subsection{Passarela da BR 101 no Engenho do Meio}

Outra passarela muito utilizada é a do Engenho do Meio, muitos estudantes do IFPE, antigo CEFET, usam essa estrutura para cruzarem diariamente a BR 101. Recentemente um caminhão colidiu com um pilar desta estrutura, que por ser uma estrutura que certamente o projetista previa esse tipo de ação, resistiu bem e continua em funcionamento. Essa OAE é uma estrutura pré-fabricada com três tabuleiros apoiados por vigas Gerber em dois pilares centrais. A corrosão de armadura nos pilares é acelerada em virtude da constante 53 umidade no local e também pelo fato de ser um ambiente bastante agressivo pelos gases da combustão dos veículos, essas corrosões podem ser observadas na Figura 17.

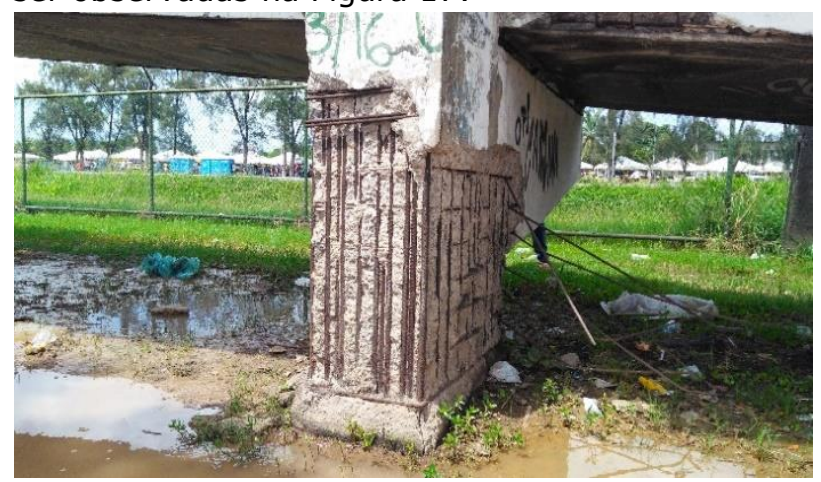

Figura 17: Corrosão de armadura em pilar.

Fonte: Próprio Autor (2019).

A falta de manutenção e reposição das juntas provocam grandes danos a estrutura acelerando o processo de corrosão além da lixiviação dos componentes do concreto como pode ser visto na Figura 18.

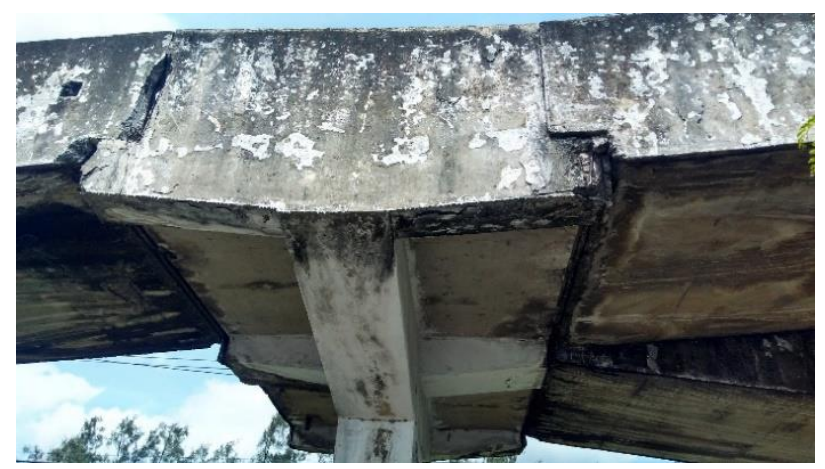

Figura 18: Estrutura com bastante infiltração nas juntas. Fonte: Próprio Autor (2019).

As sujeiras nessas estruturas entopem os drenos, possibilitando a infiltração de água que contribui como pode ser visto na Figura 19. 


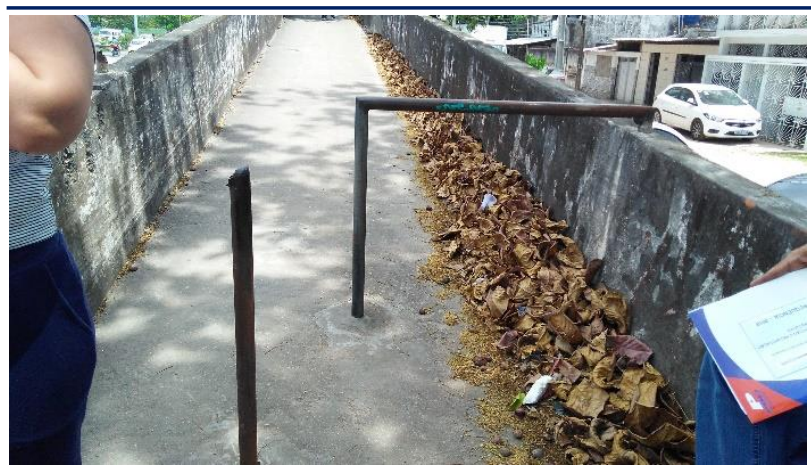

Figura 18: Folhas e lixo na parte superior das passarela Fonte: Próprio Autor (2019).

\section{CONCLUSÕES}

As passarelas têm um papel fundamental tanto para quem usa as vias como pedestres, dando segurança nas travessias de ruas, avenidas ou rodovias estaduais ou federais, quanto para os motoristas pelo simples fato de não interromper o fluxo dos veículos.

O estudo mostrou que as passarelas, por falta de manutenção, necessitam de vários reparos, inclusive estrutural. São obras construídas entre 1970 e 1980 e pelo estado em que se encontram resistiram bem a falta de cuidado, porém se não tiver uma intervenção imediata a lei de Sitter (1984) será duramente aplicada para manutenção ou recuperação destas estruturas.

As passarelas de Paratibe em Paulista estão completamente abandonadas, pois são passarelas que atendem a um público menor e não tem tanta visibilidade.

Seria interessante realizar um estudo mais aprofundado com extração de testemunhos que proporciona melhorarias no diagnóstico das OAEs identificando as origens para melhor tratar as patologias encontradas caso a caso.

No entanto a reposição do concreto, do aço, limpeza e uma pintura de proteção seria o mínimo que as essas passarelas precisam, mas reduziria muito o avanço da deterioração existente.

\section{REFERÊNCIAS}

[1] GUSMÃO, A. D. Patologia das Construções de Edifícios: Manifestações Patológicas das Fun-dações. Recife: EDUPE, 2018. 31p.
[2] HELENE, P. R. L. Manual para reparo, reforço e proteção de estruturas de concreto. São Paulo: Editora Pini. 1992.

[3] SOUZA, V. C. M, RIPPER, T. Patologia recupe-ração e reforço de estruturas de concreto. São Paulo: PINI, 2009.

[4] GOMES, C.; MONTEIRO, E.; VITÓ-RIO, A. Um estudo sobre a degradação estrutural de pontes e viadutos rodoviários.In: CONGRESSO INTERNACIONAL SOBRE PATOLOGIA E REABILITAÇÃO DE ESTRUTURAS, 13. 7-9 set. 2017, Crato. Anais... Crato: Cinpar, 2017. 15p.

[5] SANTOS, B.; INTERLANDI, C. Estruturas de Concreto Armado Patologias e suas Consequências Estudo de Caso. Engenharia Estudo e Pesquisa, ABPE, v. 16, n. 2, p.40-47, jul./dez. 2016. Disponível em: www.revistaeep.com/imagens/volume16_02/cap 05.pdf. Acesso em: 09/05/2019. p 41.

[6] SILVA, C. J. G. Uma amostra das condições estruturais e funcionais de pontes e viadutos das rodovias federais de Pernambuco. 141f. Dissertação (Mestrado em Engenharia Civil) -Universidade de Pernambuco, Recife, 2016.

[7] BRASIL, Departamento nacional de infraestrutura de transportes. Manual de Manutenção de Obras de Arte Especiai. Brasília: DNTI,2016. 17-30p.

[8] MONTEIRO, E. C. B. Fissuras. Notas de aula do Curso de Especialização. Escola Politécnica de Pernambuco, Universidade de Pernambuco, Recife, 2018. 2p.

[9] MONTEIRO, E. C. B. Fundamentos da corrosão. Notas de aula do Curso de Especialização. Escola Politécnica de Pernambuco. Universidade de Pernambuco, Recife, 2018. 5p.

[10] MONTEIRO, E. C. B. Reação álcalisagregado. Notas de aula do Curso de Especialização. Escola Politécnica de Pernambuco. Universidade de Pernambuco, Recife, 2018. 1p. 
[11] MONTEIRO, E. C. B. Manifestações patológicas em estruturas de concreto. Notas de aula do Curso de Especialização. Escola Politécnica de Pernambuco. Universidade de Pernambuco, Recife, 2018. 5p.

[12] VITÓRIO, J. A. P. Vistorias, Conservação e Gestão de Pontes e Viadutos de Concreto. In: CONGRESSO BRASILEIRO DO CONCRETO, 48., 22-27 set 2006, Rio de Janeiro. Anais... rio de Janeiro: IBRACON, 2006. 4p.

[13] SHIRAKAWA, M. A. et al. Identificação de fungos em revestimentos de argamassa com bolor evidente. In: SIMPÓSIO BRASILEIRO DE TECNOLOGIA DAS ARGAMASSAS, 1., 16-18 ago. 1995, Goiana. Anais...Goiâna: SBTA, 1995.

403p.

[14] ABNT. NBR 5674: Manutenção de edificações - Requisitos para o sistema de gestão de manutenção. Rio de Janeiro, 2012. 